\title{
Supported Phospholipid Bilayer Interaction with Components Found in Typical Room-Temperature Ionic Liquids - a QCM-D and AFM Study ${ }^{\dagger}$
}

\section{Kervin O. Evans}

New Crops and Processing Technology Research Unit, National Center for Agricultural Utilization Research, Agricultural Research Service, United States Department of Agriculture, 1815 N. University Street, Peoria, IL 61604, USA

E-mail: Kervin.Evans@ars.usda.gov; Tel.+1-309-681-6436; Fax: +1-309-681-6524

${ }^{\dagger}$ Product names are necessary to report factually on available data; however, the USDA neither guarantees nor warrants the standard of the product. In addition, the use of the name by the USDA implies no approval of the product to the exclusion of others that may be suitable.

Received: 16 October 2007; in revised form: 26 February 2008 / Accepted: 14 March 2008 / Published: 4 April 2008

\begin{abstract}
Quartz crystal microbalance with dissipation (QCM-D) monitoring and atomic force microscopy (AFM) were combined to evaluate the defects created by an ionic liquid anion and a cation in a supported phospholipid bilayer composed of zwitterionic lipids on a silica surface. The cation 1-octyl-3-methyl imidazolium $\left(\mathrm{OMIM}^{+}\right)$was shown to remove lipids from the bilayer, increase the roughness to approximately $2.8 \mathrm{~nm}(\sim 0.2$ for stable supported bilayer) and possibly redeposit lipids with entrapped water. The anion bis(trifluoromethylsulfonyl)imide $\left(\mathrm{Tf}_{2} \mathrm{~N}^{-}\right)$was found to leave distinct defects within the bilayer that had large pore-like interiors which left the surrounding bilayer intact. However, the ionic liquid 1-butyl-1-methyl pyrrolidinium bis(trifluoromethylsulfonyl)imide (BMP$\mathrm{Tf}_{2} \mathrm{~N}$ ) formed a film over the supported bilayer. This work demonstrates, for the first time, the direct effects common components of ionic liquids have on a supported phospholipids bilayer.
\end{abstract}

Keywords: Quartz crystal microbalance with dissipation (QCM-D), Supported phospholipid bilayer (SPB), Room-temperature ionic liquid (RT-IL), Atomic force microscopy (AFM), 1,2-dielaidoylphosphatidylcholine (DEPC). 


\section{Introduction}

Over the past few years, considerable interest in developing biocatalytic systems in non-aqueous environments [1-3] has developed. By conducting biocatalytic processes in non-aqueous systems, one can extend catalytic specificity of the enzymes and substrates toward new substrates in novel reactions systems. For instance, substrates such as plant sterols [4], cinnamoylated lipids [5] and commodity vegetable oils [6], which are less soluble in water, could benefit significantly from non-aqueous media in which the substrates dissolve and the reaction occurs at a reasonable rate.

Typically, bioconversion of substrates like sterols, lipids and vegetable oils is done in organic solvents [4-6] because of the substrates' incompatibility with water. However, typical organic solvents are hazardous because of their flammability and high vapor pressure. Recently, there has been a drive to overcome these hazards of organic solvents by choosing to conduct bioconversion reactions in a new class of solvents called room-temperature ionic liquids. Room-temperature ionic liquids have little or none of the hazards associated with typical organic solvents and have shown to maintain chemical/thermal stability along with high ionic conductivity $[7,8]$.

Bioconversion that uses enzymes poured into the solvent with lipids to form a "free-floating" system can be costly when it comes to separating enzyme from product or starting material. However, cost can be reduced if enzyme recovery is simplified through immobilizing the enzyme, making the bioconversion practical [9]. Bioelectrocatalysis, a more specific method of bioconversion, uses electron transfer enzyme (oxidoreductases) systems for chemical synthesis. Usually in bioelectrocatalysis, the enzyme is immobilized onto an electrode [10].

Our interest in using bioelectrocatalysis lies in our desire to use oxidoreductases to impart functionalities to fatty acid groups of plant lipids and commodity vegetable oils. Since oxidoreductases like cytochrome $\mathrm{c}$ are found bound to a membrane, our approach to stabilizing the function of the enzyme on an electrode is to incorporate phospholipid membranes.

Although it has been demonstrated that room-temperature ionic liquids will support biocatalytic [11-16] and enzymatic reactions [14-17], it is unclear what effects the ionic liquids would have on lipids in the proximity of the interface between the electrode and enzyme which is readily used in biocatalytic reactions. In other words, the question to answer is what happens to lipid membranes that are used as a reactor/immobilization surface for the enzyme [9] in ionic liquids. This study was undertaken to develop an understanding of the resultant interaction between individual components of ionic liquids and phospholipids bilayers on a surface by exploring the interaction of a common 1-alkyl3-methyl imidazolium cation and a common anion species found in several room-temperature ionic liquids, focusing on two components from a previous study where membrane disruption occurred for phosphatidylcholine vesicles free in solution [18]. The intent is to shed more light on the details of interactions of these components with phosphatidylcholine bilayers.

\section{Results and Discussion}

2.1. Effect of 1-Octyl-3-Methyl imidazolium (OMIM+) on 1,2-dielaidoylphosphatidylcholine (DEPC) Supported Phospholipid Bilayer (SPB)

For the current study, DEPC was selected because its phase transition occurs between 0 and $23{ }^{\circ} \mathrm{C}\left(\sim 13^{\circ} \mathrm{C}\right)$. All measurements were conducted with DEPC vesicles at $125 \mu \mathrm{M}$ and at $20^{\circ} \mathrm{C}$ (this 
ensures vesicle interactions with 1-octyl-3-methyl imidazolium chloride (OMIM-Cl) and $\mathrm{LiTf}_{2} \mathrm{~N}$ are not affected by lipids in a gel phase).

Quartz crystal microbalance with dissipation monitoring (QCM-D) is a well established tool for monitoring supported phospholipid bilayer formation and interaction with various materials [19]. In recent years, several studies have been conducted to demonstrate the effect that the lipid composition of vesicles [20], buffer contents [21] and ionic strength [22] have on SPB formation on a silicon dioxide surface. In these listed previous studies, the lipid head group was phosphatidylcholine and the tail groups were completely saturated (1,2-dimyristoylphosphatidylcholine - DMPC) or contained just one point of unsaturation (1,2-dioleoylphosphatidylcholine - DOPC). In the case for DMPC (phase transition of $23^{\circ} \mathrm{C}$ ), it was found that the presence of a minimum of $90 \mathrm{mM} \mathrm{NaCl}$ was required for vesicles to form a SPB through a two-step pathway which started with the collection of vesicles on the surface at a critical density followed by the final SPB formation [22]. Similarly, conditions were found for this study where a bilayer was formed that was consistent with known studies of SPB formation on silica $[19,21-24]$. Therefore, all buffers from this point contained $100 \mathrm{mM} \mathrm{NaCl}$ in addition to any ionic liquid. The relationship between the change in absorbed mass and corresponding frequency change has been described by Sauerbrey [25] using the following equation:

$$
\Delta m=-\frac{C}{n} \Delta f
$$

where $C$ is the mass-sensitivity constant $\left(17.7 \mathrm{ng} / \mathrm{cm}^{2} / \mathrm{Hz}\right.$ at $\left.5 \mathrm{MHz}\right), f$ is the frequency, $n$ is the overtone number $(1,3,5$, or 7$)$, and $m$ is the adsorbed mass. Using this relationship which was proven to hold for thin, rigid films [24] and to underestimate unruptured vesicles (soft material) to within 5\% error [26], it was found that the SPB formed had a mass of $\sim 523 \mathrm{ng} / \mathrm{cm}^{2}$ (Table 1), which is slightly more than typically reported for SPB on $\mathrm{SO}_{2}$ [23, 24], 434 and $468 \mathrm{ng} \mathrm{cm}{ }^{-2}$, respectively. This suggests that some vesicles were still unruptured with some entrapped buffer remaining. Upon exposing the SPB to $\mathrm{OMIM}^{+}$for $15 \mathrm{~min}$ and flushing with buffer to remove the $\mathrm{OMIM}^{+}$, it was revealed that there was a loss of mass $\left(\sim 438 \mathrm{ng} / \mathrm{cm}^{2}\right.$ remaining). Because the resulting mass is near the values reported for a rigid thin SPB, it is reasonable to conclude that residual vesicles were ruptured by $\mathrm{OMIM}^{+}$(this is also inferred from fluorescent measurements done by Evans [18]). Consequently, the entrapped buffer was released resulting in the loss of mass. However, closer examination of the data after $\mathrm{OMIM}^{+}$was rinsed away shows that there is a change in the frequency dependence of the signals and an increase in dissipation (Table 1). The increased dissipation change after rinsing away the bulk of $\mathrm{OMIM}^{+}$indicates that there was an increase in effective viscosity of the adsorbed film. Further evidence of increased effective viscosity is indicated by the separation of each frequency $(15,25$, $35 \mathrm{MHz}$ ) and corresponding dissipation values after $\mathrm{OMIM}^{+}$was flushed away (Figure 1), possibly the result of a softer layer bound to the crystal [27]. However, effects due to changes in surface roughness [28], changes in the coupling between the bilayer the surface, and/or a combination of changes due to film thickness and viscoelastic properties are not distinguishable and therefore not ruled out. 
Table 1. QCM-D parameters of SPB before and after exposure to $\mathrm{OMIM}^{+}$and $\mathrm{Tf}_{2} \mathrm{~N}^{-}$.

\begin{tabular}{ccccccc}
\hline RT-IL & \multicolumn{2}{c}{$\Delta \mathbf{f}_{\mathbf{3}}(\mathbf{H z})^{\mathbf{a}, \mathbf{b}}$} & \multicolumn{2}{c}{$\Delta \mathbf{D}_{\mathbf{3}} \mathbf{( 1 0}^{-\mathbf{6}} \mathbf{b}^{\mathbf{b}}$} & \multicolumn{2}{c}{ Mass $\left(\mathbf{n g} / \mathbf{c m}^{\mathbf{2}}\right)^{\mathbf{c}}$} \\
Component & Before & After & Before & After & Before & After \\
\hline $\mathrm{OMIM}^{+}$ & $-29.0 \pm 3.2$ & $-24.2 \pm 5.5$ & $0.61 \pm 1.2$ & $1.1 \pm 2.1$ & $522 \pm 58$ & $437 \pm 97$ \\
$\mathrm{Tf}_{2} \mathrm{~N}^{-}$ & $-30.0 \pm 2.6$ & $-25.0 \pm 2.4$ & $0.36 \pm 0.47$ & $0.026 \pm 0.005$ & $542 \pm 32$ & $452 \pm 20$ \\
$\mathrm{BMP}_{-} \mathrm{Tf}_{2} \mathrm{~N}$ & $-26.0 \pm 0.1$ & $-28.2 \pm 0.8$ & $0.03 \pm 0.08$ & $1.1 \pm 0.1$ & $460 \pm 3$ & $500 \pm 14$ \\
\hline
\end{tabular}

(a) Standard deviation was determined from 2 or 3 experiments; (b) Frequency and dissipation values were reported from the $3^{\text {rd }}$ overtone; (c) Sauerbrey relationship was used to estimate the mass.

Figure 1. QCM-D response at 15 (black), 25 (red) and 35 (green) MHz as DEPC vesicles form a SPB on $\mathrm{SiO}_{2}$ and interact with 1-octyl-3-methyl imidazolium chloride at $20^{\circ} \mathrm{C}$.

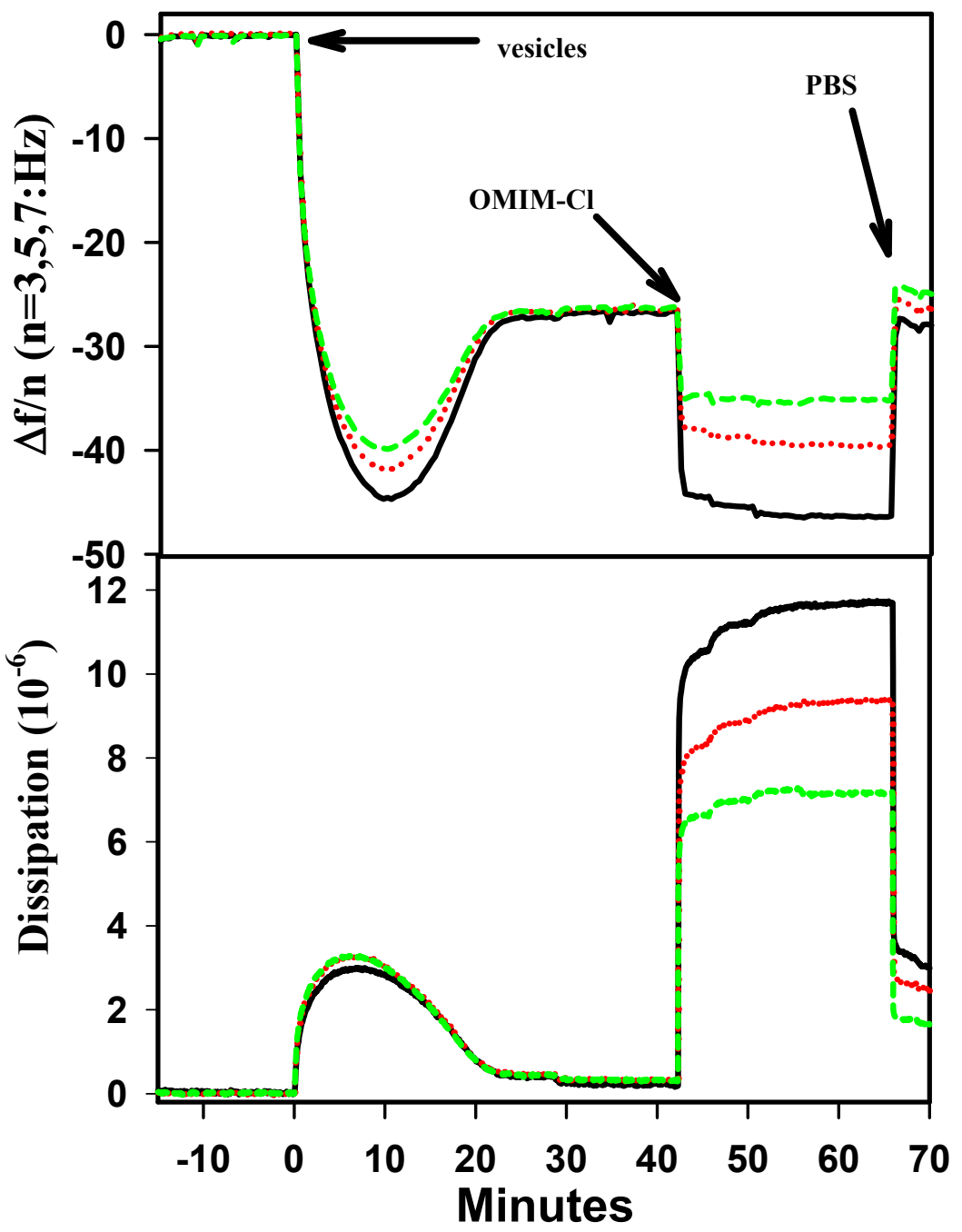

To further evaluate the effect $\mathrm{OMIM}^{+}$had on DEPC as a SPB, AFM imaging was conducted under the same conditions as the QCM-D measurements. Figure 2a exhibits the SPB on a silica wafer prior to and Figure $2 \mathrm{~b}$ is the SPB 15 min after exposure to $\mathrm{OMIM}^{+}$. The image was obtained using tapping mode with a scan rate of $\sim 2.5 \mathrm{~Hz}$ over a $400 \mathrm{~nm}$ by $400 \mathrm{~nm}$ area. Dark areas in Figure 2a show where 
the SPB was removed by $\mathrm{OMIM}^{+}$. A cross-sectional analysis of the SPB (Figure $2 \mathrm{~b}$ ) revealed that the topography had regions with a maximum height of nearly $7.5 \mathrm{~nm}$ with an average roughness of $2.8 \mathrm{~nm}$ (compared to $0.2 \mathrm{~nm}$ for a defect-free bilayer). Interpretation of the AFM height images after $\mathrm{OMIM}^{+}$ was rinsed away is that the bilayer was solubilized such that it was inhomogeneous on the silica, forming softer regions where water was possibly entrapped again. This interpretation fits well with the measured QCM-D data. Therefore, it is reasonable to conclude that such a change in the SPB topography would result in a non-uniform, softer bilayer that couples less to the silica surface (as indicated by the dissipation change after exposure to $\mathrm{OMIM}^{+}$). However, aggregation formation is not ruled out. Further support of the change in softness of the SPB after exposure to OMIM-Cl is suggested from the phase image of the SPB (Figure 2c) where there is quite a difference in phase of the low and high areas of image. Phase imaging is based on a difference in the oscillation of the AFM tip as it is driven by the piezo and the oscillation due to the tip responding to interactions with a surface. Because the phase contrast of a SPB is interpreted as a change in softness [29], the interpretation of Figure 2c is that the softness of the SPB varied over the surface after exposure to $\mathrm{OMIM}^{+}$.

An understanding of the mechanism of membrane disruption caused by $\mathrm{OMIM}^{+}$is also possible when viewing the chemical structure of $\mathrm{OMIM}^{+}$(Figure 2e). As Figure 2e shows, $\mathrm{OMIM}^{+}$has a hydrophobic region and a polar region (charged imidazolium ring). With these amphiphilic properties, it is clear that $\mathrm{OMIM}^{+}$probably can form aggregates $[30,31]$ and solubilize the supported bilayer as some mixed micelle structure.

\subsection{Interaction of $T_{2} N$ with a $S P B$}

Figure 3 displays the frequency and dissipation changes associated with vesicle adsorption, fusion to form a SPB and subsequent interaction with $\mathrm{Tf}_{2} \mathrm{~N}^{-}$on a $\mathrm{SiO}_{2}$ surface. Table 1 displays a comparison of the frequency and dissipation changes before and after exposure to $\mathrm{Tf}_{2} \mathrm{~N}^{-}$. The data indicates a slight reduction in frequency change after the SPB was exposed to $\mathrm{Tf}_{2} \mathrm{~N}^{-}$. This difference in frequency before and after $\mathrm{Tf}_{2} \mathrm{~N}^{-}$exposure translates into a difference in mass present (confirmed by t-test analysis where $\mathrm{p}$ was 0.0358 ).

AFM imaging was done to confirm the interpretation made from the QCM-D data. AFM tapping mode imaging show that the bilayer after exposure to $\mathrm{Tf}_{2} \mathrm{~N}^{-}$contained large defects approximately 400-600 nm wide (Figure 4a). Height measurements (Figure 4b) revealed that the defects had a maximal depth $(\Delta \mathrm{H})$ of $5.5 \pm 1.1 \mathrm{~nm}$ (tapered interior is an artifact of the AFM tip probe). The AFM image data is consistent with the QCM-D data in that $\mathrm{Tf}_{2} \mathrm{~N}^{-}$caused a loss of lipids from bilayer but left the remaining bilayer undisturbed and rigidly bound to $\mathrm{SiO}_{2}$. This is also consistent with recently measured fluorescence data on intact vesicles in the presence of $\mathrm{Tf}_{2} \mathrm{~N}^{-}$[18], although it is unclear what role curvature of the vesicles or surface interactions with the supported bilayer played in each case. It possible though, that the chemical structure of $\mathrm{Tf}_{2} \mathrm{~N}^{+}$(Figure 4c) may play a more direct role in disrupting the membrane. $\mathrm{Tf}_{2} \mathrm{~N}^{-}$may form dendrimer-like structures that are capable of disrupting the bilayer by removing lipids and creating nanoscale holes which leave behind nearly bare substrate in places [32-34]. 
Figure 2. AFM image of DEPC SPB after 15 min exposure to OMIM-Cl in PBS (10mM potassium phosphate, $100 \mathrm{mM} \mathrm{NaCl}, \mathrm{pH} 7$ ) solution. Scan size was $400 \times 400 \mathrm{~nm}^{2}$ in tapping mode with a minimum force by keeping the amplitude set point and drive amplitude as low as possible. (a) SPB prior to OMIM-Cl exposure; (b) SPB after 15min exposure to OMIM-Cl; $\quad$ (c) Cross-section graph of the topography of the SPB after exposure to OMIM-Cl for 15 min displays the "hills and valleys" that remain; (d) Phase image of SPB after exposure to OMIM-Cl; (e) space-filled model of $\mathrm{OMIM}^{+}$.

$2 \mathbf{a}$
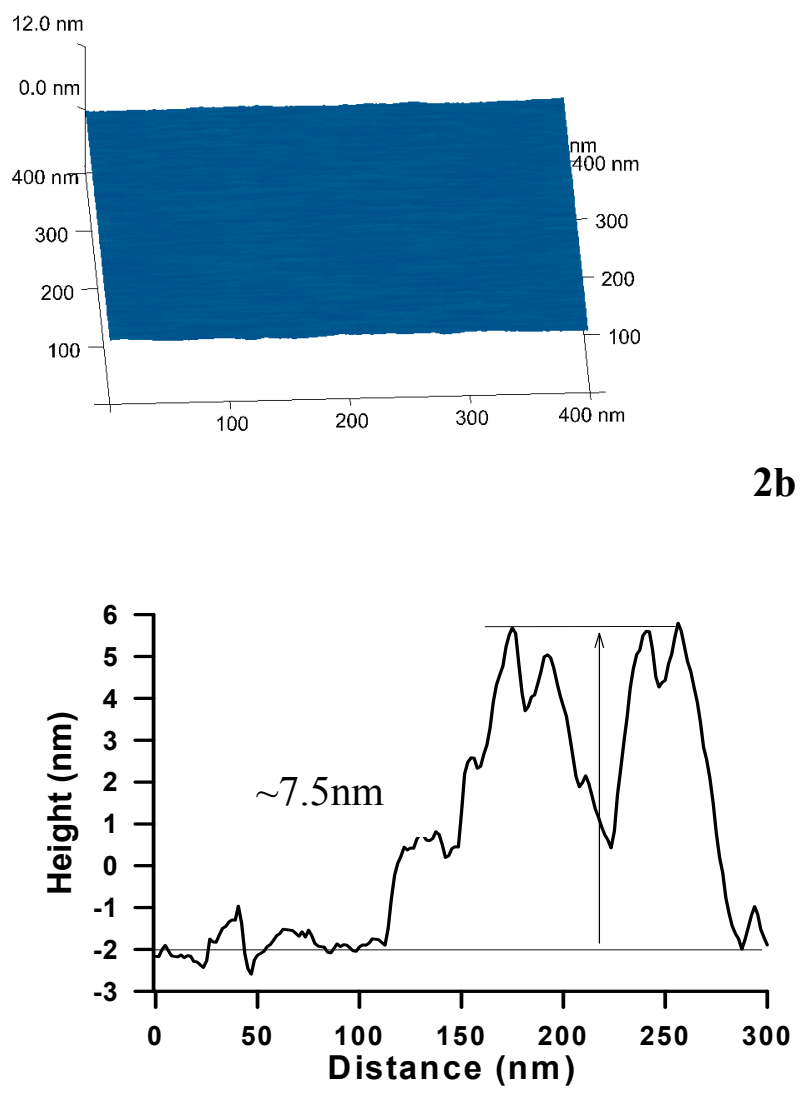

$2 \mathrm{c}$ 2b

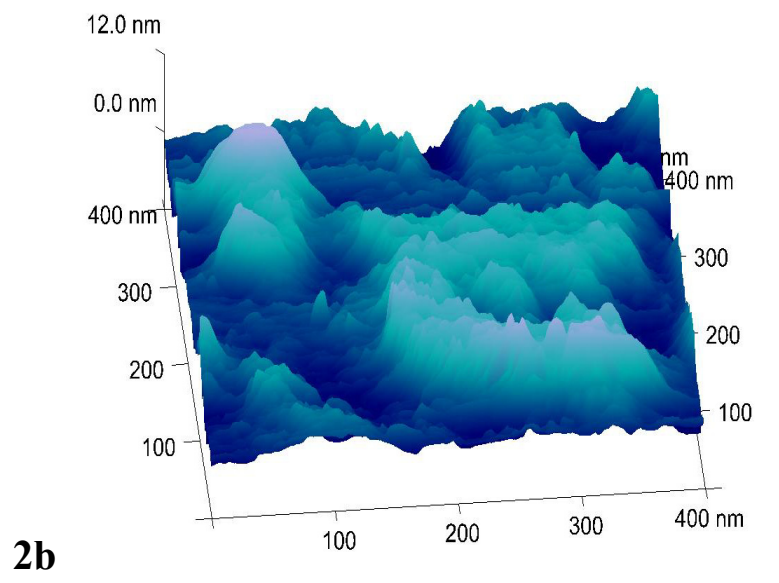

2d

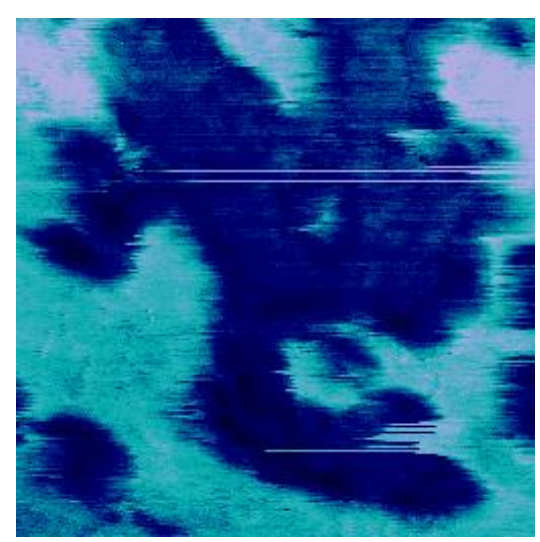

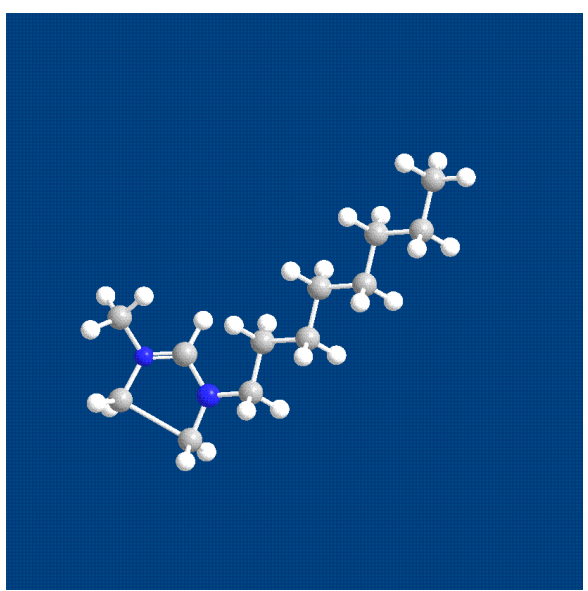




\subsection{Result of $B M P-T f_{2} N$ Interaction with $S P B$}

DEPC vesicles were allowed to adsorb to a silica surface to form a supported bilayer. The supported bilayer was incubated with $\mathrm{BMP}-\mathrm{Tf}_{2} \mathrm{~N}$ for at least $30 \mathrm{~min}$. Figure $6 \mathrm{a}$ shows the typical QCM-D response of a silica crystal at 15, 25, and $35 \mathrm{MHz}$ during the experiment. The data clearly shows a slight increased frequency change after the supported bilayer was exposed to BMP-Tf $2 \mathrm{~N}$ at $52 \mathrm{mg} / \mathrm{ml}$ and subsequently rinsed several times with buffer. The data also shows a highly dissipative system after the rinses, suggesting the existence of a loosely bound layer. This now loosely bound layer could result from either a thin layer of BMP- $\mathrm{Tf}_{2} \mathrm{~N}$ loosely adsorbing onto the SPB or from BMP$\mathrm{Tf}_{2} \mathrm{~N}$ molecules that have inserted into the SPB and caused portions of the bilayer to be bound loosely to the silica. Assuming that the frequency change is strictly proportional to mass even when there is large dissipation, then there was an increase in mass after exposure to $\mathrm{BMP}-\mathrm{Tf}_{2} \mathrm{~N}$ (table 1) and the former is favored. Figure $6 \mathrm{~b}$ shows an image of a typical SPB interacting with $\sim 52 \mathrm{mg} / \mathrm{ml} \mathrm{BMP}-\mathrm{Tf}_{2} \mathrm{~N}$ after incubation. The image shows a surface that contains uneven or "rippled" features where the roughness over these "rippled" areas is approximately $6 \mathrm{~nm}$, which is considerably greater than the roughness $(\sim 0.3 \mathrm{~nm})$ of the same area just prior to $\mathrm{BMP}-\mathrm{Tf}_{2} \mathrm{~N}$. The area roughness (an average height above the surface) of the "rippled" region is in close agreement with the estimate thickness $(\sim 5.4 \mathrm{~nm}$; determined from Voight modeling) of the adsorbed material after the buffer rinses. In addition, the area marked by the star (top segment of image) revealed an area of roughness close to the value for the untreated SPB. The interpretation of the AFM and QCM-D data together is that BMP-Tf $2 \mathrm{~N}$ formed a thin layer over the SPB, although lipid removal is not ruled out.

\subsection{Conclusions}

The present work characterized the nature of the membrane defects created by two RT-IL components of interest, $\mathrm{OMIM}^{+}$and $\mathrm{Tf}_{2} \mathrm{~N}^{-}$. It was shown that $\mathrm{OMIM}^{+}$disrupted a membrane and caused a change in bilayer "softness". $\mathrm{Tf}_{2} \mathrm{~N}^{\text {}}$, on the other hand, created large, stable pore-like defects in a SPB. The room-temperature ionic liquid BMP- $\mathrm{Tf}_{2} \mathrm{~N}$ resulted in an adsorbed layer of ionic liquid. Clearly, the tuneability of physical properties of ionic liquid also dictates the effects the ionic liquids have on SPB. And, the combined use of QCM-D and AFM clearly proves to be powerful tools to characterize the different effects ionic liquids exhibit on SPB. 
Figure 3. QCM-D response (at 15, 25, and $35 \mathrm{MHz}$ ) during DEPC SPB formation and interaction with lithium bis(trifluoromethylsulfonyl)imide $\left(\mathbf{T f}_{2} \mathbf{N}^{-}\right)$at $500 \mathrm{mM}$ on $\mathrm{SiO}_{2}$ at $20^{\circ} \mathrm{C}$. (The peak feature after rinsing the ionic liquid away is due to incomplete mixing of the two solutions).

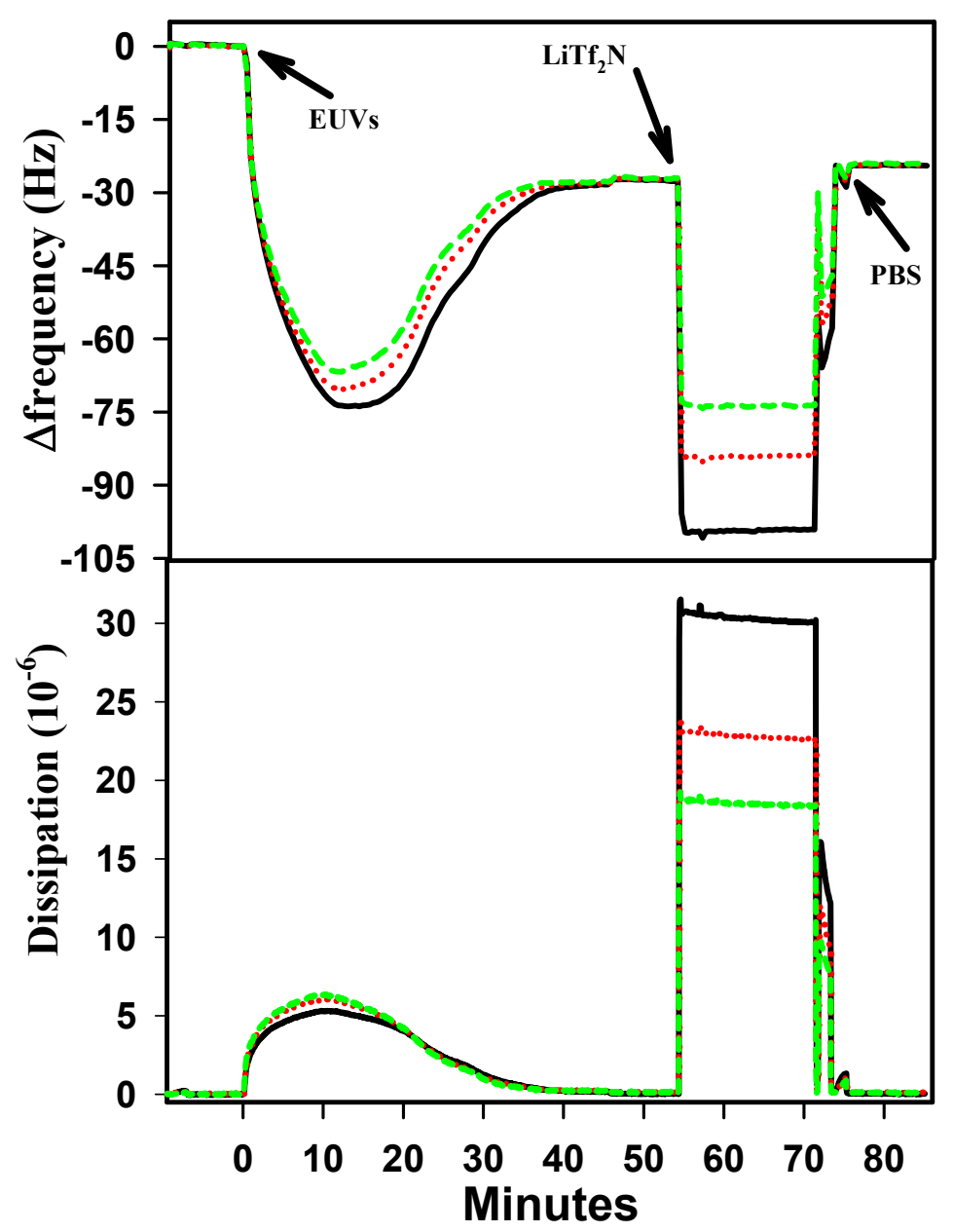

Figure 4. (a) TM-AFM image of DEPC SPB after exposure to $\operatorname{LiTf}_{2} \mathrm{~N}$ for $15 \mathrm{~min}$. (b) Height profile of typical defects found in a SPB after exposure to $\operatorname{LiTf}_{2} \mathrm{~N}$; (c) space-filled model of $\mathrm{Tf}_{2} \mathrm{~N}^{-}$.

4a

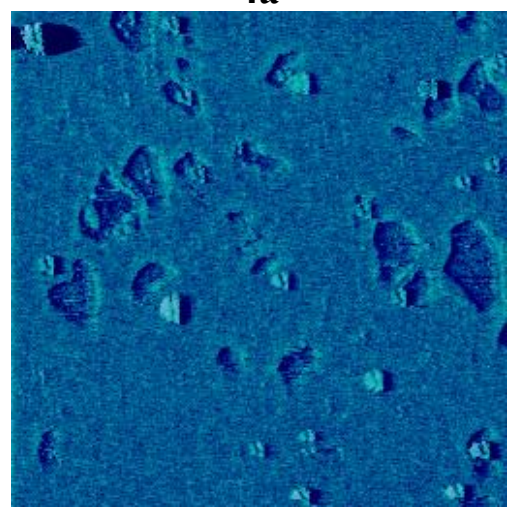

4b

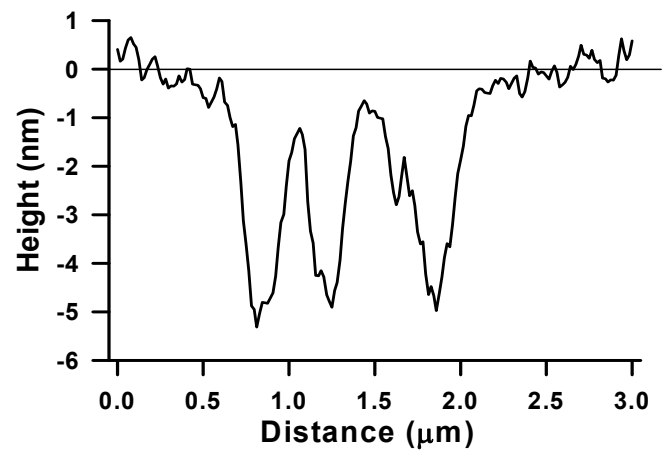

4c

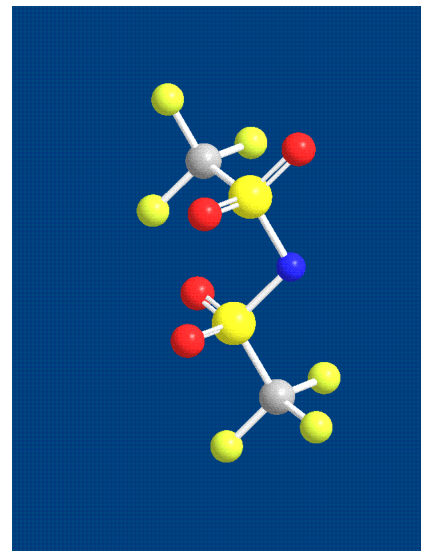


Figure 5. Typical QCM-D response (at 15, 25, and $35 \mathrm{MHz}$ ) during DEPC SPB formation and interaction with 1-butyl-1-methylpyrrolidinium bis(trifluoromethylsulfonyl)imide (BMP-Tf $2 \mathbf{N}$ ) on $\mathrm{SiO}_{2}$ at $20^{\circ} \mathrm{C}$. (The spike feature after adding the ionic liquid is due to a temperature surge).

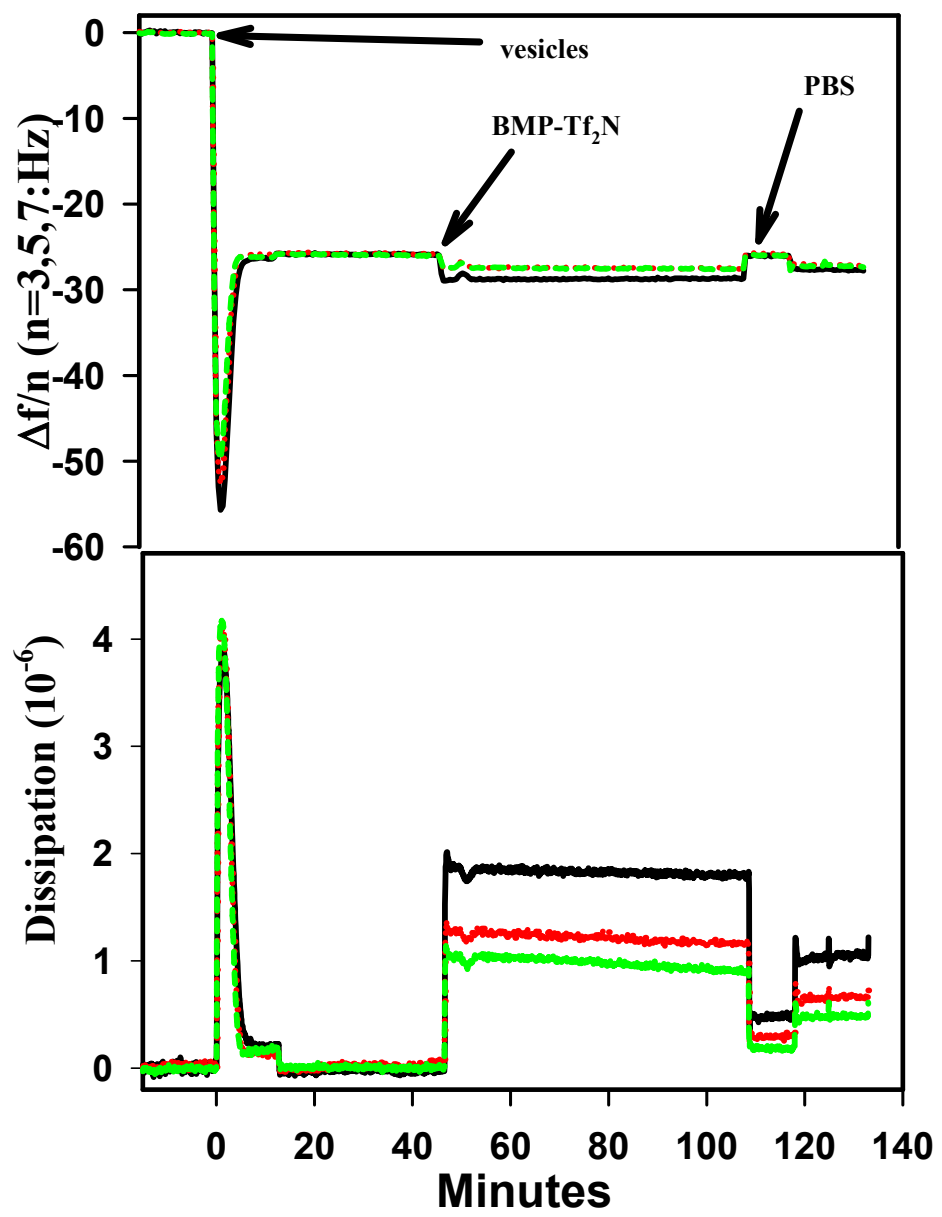

Figure 6. (a) Tapping Mode-AFM topographical image of BMP- $\mathrm{Tf}_{2} \mathrm{~N}$ effects on a SPB on silica. The black star highlights an area as smooth as an untreated SPB; circles highlight areas where ripples were formed; (b) Chem3D Pro structure of $\mathrm{BMP}-\mathrm{Tf}_{2} \mathrm{~N}$.

6a

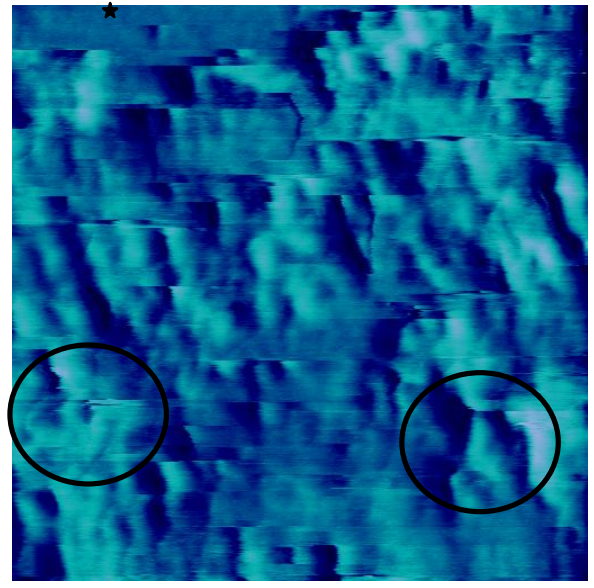

6b

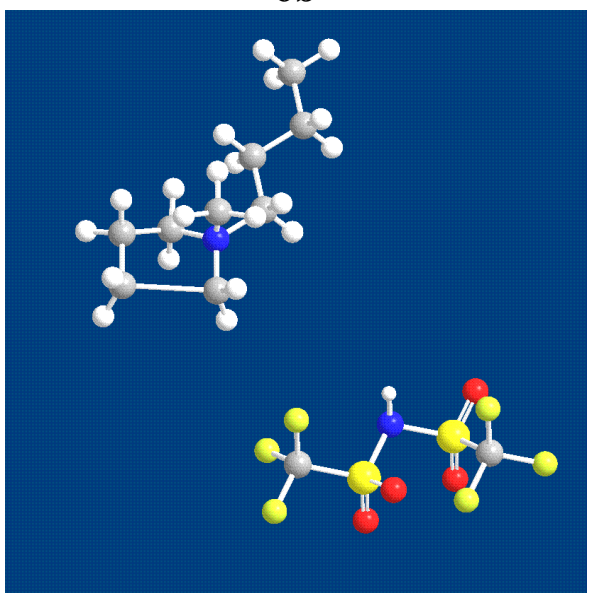




\section{Experimental Section}

\subsection{Extruded unilamellar vesicles preparation}

1,2-Dielaidoyl-sn-glycero-3-phosphatidylcholine in chloroform at $10 \mathrm{mg} / \mathrm{ml}$ (purchased without further purification from Avanti Polar Lipids, Inc., Alabaster, AL) was stored under argon at $-20^{\circ} \mathrm{C}$. An aliquot of lipids was placed in a brown, amber vial and dried under a gentle stream of argon to achieve a thin film of lipids at the bottom of the vial. Lipids were further dried in a rotary evaporator for an hour and left under house vacuum overnight to remove remaining traces of chloroform. Dried lipids were reconstituted in $10 \mathrm{mM}$ potassium phosphate buffer, $100 \mathrm{mM} \mathrm{NaCl}$ at $\mathrm{pH} 7$ (appropriate amounts of potassium phosphate monobasic $-\mathrm{KH}_{2} \mathrm{PO}_{4}$ and dibasic $-\mathrm{K}_{2} \mathrm{HPO}_{4}$ from Fisher Scientific at ACS grade or better; $\mathrm{NaCl}$ was also from Fisher Scientific) to give a final lipid concentration of $5 \mathrm{mM}$. The rehydrated lipids were kept at room temperature (well-above the phase transition temperature of $13^{\circ} \mathrm{C}$ ) and vortexed periodically for one hour. The multi-unilamellar vesicles created from the periodic vortexing were put through five cycles of freeze-thaw that was carried out in dry ice in 2propanol (Sigma-Aldrich Chemicals, St. Louis, MO) and nanopure water at $18.2 \mathrm{M} \Omega \mathrm{cm}$ (Barnstead Nanopure water purification system, model \# D11911) heated to $50^{\circ} \mathrm{C}$, respectively. The MUVs were manually extruded 31-times through two 50-nm pore size filters using a LiposoFast hand-held extruder (AVESTIN, Inc, Ottawa, Canada). The sizes of the extruded, unilamellar vesicles were determined through dynamic light scattering (Nicomp Submicron Particle Sizer, Particle Sizing Systems, Inc., Santa Barbara, CA) to have a diameter $\sim 83 \mathrm{~nm}$. Vesicles were kept under argon and used within three days of extrusion.

1-Octyl-3-methyl imidazolium chloride and lithium bis(trifluoromethylsulfonyl)imide were purchased (Sigma-Aldrich Chemicals) at the highest purity available and dissolved in PBS to give final stock concentrations of 100 and $500 \mathrm{mM}$, respectively. All water used was obtained from the above-mentioned water purification system. 1-Butyl-1-methyl pyrrolidinium bis(trifluoromethylsulfonyl)imide was purchased from EMD Chemicals (Gibbstown, NJ). 1-Butyl-1methyl pyrrolidinium bis(trifluoromethylsulfonyl)imide is only partially miscible with water. Therefore, it was weighed into an empty, clean amber vial using a syringe. Buffer was added and the mixture was vortexed just prior to injection into the cell where a SPB was formed.

\subsection{Quartz crystal microbalance with dissipation monitoring}

A Q-Sense D300 system with an axial flow sample chamber (Q-Sense, Inc., Glen Burnie, MD) was used to record vesicle adsorption, bilayer formation and interaction with the RT-ILs of interest. A brief background of QCM methods and a complete description of the instrument were presented by Patel and Frank [35] and Rodahl and Kasemo [36], respectively. Briefly, experiments were run such that gravity caused the samples to flow into the crystal chamber. Flow rate was reduced to minimize incomplete mixing. The system was allowed to equilibrate in the buffer for at least 20 min before addition of vesicle to reduce drift. All experiments were conducted at $23^{\circ} \mathrm{C}$. Frequency (as well dissipation) shifts were recorded for all four frequencies (the fundamental frequency of $5 \mathrm{MHz}$ and the $3^{\text {rd }}, 5^{\text {rd }}$ and $7^{\text {th }}$ overtones at 15,25 and $35 \mathrm{MHz}$, respectively). Data were recorded using Q-Soft 301 
software version 1.6.16 and analyzed using Q-Tools software version 2.0.6.79 (software was supplied with Q-Sense system). Silicon dioxide crystals purchased from Q-Sense were cleaned by first rinsing in water followed by an ethanol rinse and drying under a gentle nitrogen stream. The crystals were next placed into an UV/Ozone chamber (Bioforce Nanosciences, Ames, IA) for $10 \mathrm{~min}$ [37]. The crystals were submerged in $2-4 \%(\mathrm{v} / \mathrm{v})$ sodium dodecyl sulfate in nanopure water for $30 \mathrm{~min}$ to remove any biological contaminants $[38,39]$, followed by rinses with water and then ethanol, drying with a nitrogen stream, and a final cycle in the UV/Ozone cleaner just prior to use.

\subsection{Atomic Force Microscopy}

AFM imaging was conducted in PBS using a multimode system equipped with a Nanoscope IV controller, E-scanner and heater (Veeco, Inc., Santa Barbara, CA). A fluid cell with a silicon o-ring was utilized to reduce evaporation. Silicon nitride cantilevers with a nominal spring constant of 0.06 $\mathrm{N} / \mathrm{m}$ were used. Cantilevers were cleaned by soaking in ethanol for $15 \mathrm{~min}$, allowed to air dry and exposed to UV/ozone for $10 \mathrm{~min}$ just prior to use. Fluid cell and tubing were rinsed in water and then ethanol, followed by sonication for $10 \mathrm{~min}$ in water and a final rinse of water followed by an ethanol rinse. Fluid cell and tubing were dried using a nitrogen stream. All images were taken in tapping mode, using a minimum force to eliminate any artifacts created by the tip (minimum force was accomplished by maintaining the lowest drive amplitude and lowest set point amplitude possible without loosing contact with the surface). Scan speed was set to 1-2.5 Hz. Silica wafers (Wafer World, Inc., West Palm Beach, FL) were cut to size with a diamond scribe and epoxied onto metal pucks at least $24 \mathrm{hrs}$ prior to imaging. The fluid cell was allowed to equilibrate for $30 \mathrm{~min}$ with PBS that was flowed into the cell. Vesicles were flowed into the cell at $125 \mu \mathrm{M}$, allowed to adsorb onto the silica surface and form a bilayer within $15 \mathrm{~min}$. Unabsorbed vesicles were flushed away with buffer. The SPB was then exposed to OMIM-Cl (at $100 \mathrm{mM}$ ) or $\operatorname{LiTf}_{2} \mathrm{~N}$ (at $500 \mathrm{mM}$ ) for $15 \mathrm{~min}$, flushed with buffer and imaged after 15-45 min equilibration (PBS and RT-IL were maintained at $20^{\circ} \mathrm{C}$ ).

\section{Acknowledgements}

The author is greatly indebted to Kendra Brandon for providing technical assistance in performing the QCM-D measurements for this work and to Garyia Hawkins in performing AFM measurements as a part of a summer research project. Garyia Hawkins was supported through a 2006 Project SEED volunteer fellowship from the American Chemical Society.

\section{References and Notes}

[1] Hudson, E.P.; Eppler, R.K.; Clark, D.S. Biocatalysis in semi-aqueous and nearly anhydrous conditions. Curr Opin Biotechnol 2005 16, 637-643.

[2] Sardessai, Y.N.; Bhosle, S. Industrial potential of organic solvent tolerant bacteria. Biotechnol Prog 2004 20, 655-660.

[3] Wang, P.; Dai, S.; Waezsada, S.D.; Tsao, A.Y.; Davison, B.H. Enzyme stabilization by covalent binding in nanoporous sol-gel glass for nonaqueous biocatalysis. Biotechnol Bioeng 200174 , 249-255. 
[4] Perez, C.; Falero, A.; Duc, H.L.; Balcinde, Y.; Hung, B.R. A very efficient bioconversion of soybean phytosterols mixtures to androstanes by mycobacteria. J Ind Microbiol Biotechnol 2006 33, 719-723.

[5] Karboune, S.; Safari, M.; Lue, B.-M.; Yeboah, F.K.; Kermasha, S. Lipase-catalyzed biosynthesis of cinnamoylated lipids in a selected organic solvent medium. J Biotechnol 2005 119, 281-290.

[6] Noureddini, H.; Gao, X.; Philkana, R.S. Immobilized Pseudomonas cepacia lipase for biodiesel fuel production from soybean oil. Bioresourc Technol 2005 96, 769-777.

[7] Quinn, B.M.; Ding, Z.; Moulton, R.; Bard, A.J. Novel Electrochemical Studies of Ionic Liquids. Langmuir 2002 18, 1734-1742.

[8] Zhao, H.; Malhotra, S.V. Applications of ionic liquids in organic synthesis. Aldrichim Acta 2002, 35 75-83.

[9] Xuebing, X. Engineering of enzymatic reactions and reactors for lipid modification and synthesis. Eur J Lipid Sci Technol 2003 105, 289-304.

[10] Wu, Y.; Hu, S. Biosensors based on direct electron transfer in redox proteins. Microchim Acta 2007 159, 1-17.

[11] Pfruender, H.; Jones, R.; Weuster-Botz, D. Water immiscible ionic liquids as solvents for whole cell biocatalysis. J Biotechnol BioPerspectives 2006 124, 182-190.

[12] Reetz, M.T.; Wiesenhofer, W.; Francio, G.; Leitner, W. Biocatalysis in ionic liquids: batchwise and continuous flow processes using supercritical carbon dioxide as the mobile phase. Chem Commun (Camb) 2002 992-993.

[13] Laszlo, J.A.; Compton, D.L. Alpha-chymotrypsin catalysis in imidazolium-based ionic liquids. Biotechnol Bioeng 2001 75, 181-186.

[14] van Rantwijk, F.; Lau, R.M.; Sheldon, R.A. Biocatalytic transformations in ionic liquids. Trends Biotechnol 2003 21, 131-138.

[15] Yang, Z.; Pan, W. Ionic liquids: Green solvents for nonaqueous biocatalysis. Enzyme Microb Technol 2005 37, 19-28.

[16] Kragl, U.; Eckstein, M.; Kaftzik, N. Enzyme catalysis in ionic liquids. Curr Opin Biotechnol 2002 13, 565-571.

[17] Laszlo, J.A.; Compton, D.L. Comparison of peroxidase activities of hemin, cytochrome c and microperoxidase-11 in molecular solvents and imidazolium-based ionic liquids. $J$ Mol Catal B Enzym 2002 18, 109-120.

[18] Evans, K.O. Room-temperature ionic liquid cations act as short-chain surfactants and disintegrate a phospholipid bilayer. Colloids Surf A 2005 274, 11-17.

[19] Richter, R.P.; Berat, R.; Brisson, A.R. Formation of Solid-Supported Lipid Bilayers: An Integrated View. Langmuir 2006 22, 3497-3505.

[20] Seantier, B.; Breffa, C.; Felix, O.; Decher, G. In situ investigations of the formation of mixed supported lipid bilayers close to the phase transition temperature. Nano Lett 2004 4, 5-10.

[21] Seantier, B.; Breffa, C.; Felix, O.; Decher, G. Dissipation-Enhanced Quartz Crystal Microbalance Studies on the Experimental Parameters Controlling the Formation of Supported Lipid Bilayers. J Phys Chem B 2005 109, 21755-21765. 
[22] Boudard, S.; Seantier, B.; Breffa, C.; Decher, G. Felix, O. Controlling the pathway of formation of supported lipid bilayers of DMPC by varying the sodium chloride concentration. Thin Solid Films 2006 495, 246-251.

[23] Richter, R.; Mukhopadhyay, A.; Brisson, A. Pathways of Lipid Vesicle Deposition on Solid Surfaces: A Combined QCM-D and AFM Study. Biophys J 2003 85, 3035-3047.

[24] Keller, C.A.; Kasemo, B. Surface specific kinetics of lipid vesicle adsorption measured with a quartz crystal microbalance. Biophy J 1998 75, 1397-1402.

[25] Sauerbrey, G. The use of quartz oscillators for weighing thin layers and for microweighing. $Z$ Phys 1959 155, 206-222.

[26] Reimhult, E.; Hook, F.; Kasemo, B. Vesicle Adsorption on $\mathrm{SiO}_{2}$ and $\mathrm{TiO}_{2}$ : Dependence on Vesicle Size. J Chem Phys 2002 117, 7401-7404.

[27] Hook, F.; Kasemo, B.; Nylander, T.; Fant, C.; Sott, K.; Elwing, H. Variations in coupled water, viscoelastic properties, and film thickness of a Mefp-1 protein film during adsorption and crosslinking: a quartz crystal microbalance with dissipation monitoring, ellipsometry, and surface plasmon resonance study. Anal Chem 2001 73, 5796-5804.

[28] Daikhin, L.; Urbakh, M. Effect of Surface Film Structure on the Quartz Crystal Microbalance Response in Liquids. Langmuir 1996 12, 6354-6360.

[29] Leonenko, Z.V.; Carnini, A.; Cramb, D.T. Supported planar bilayer formation by vesicle fusion: the interaction of phospholipid vesicles with surfaces and the effect of gramicidin on bilayer properties using atomic force microscopy. Biochim Biophys Acta Biomemb 2000 1509, 131-147.

[30] Singh, T.; Kumar, A. Aggregation Behavior of Ionic Liquids in Aqueous Solutions: Effect of Alkyl Chain Length, Cations, and Anions. J Phys Chem B 2007 111, 7843-7851.

[31] Bowers, J.; Butts, C.P.; Martin, P.J.; Vergara-Gutierrez, M.C. Aggregation Behavior of Aqueous Solutions of Ionic Liquids. Langmuir 2004 20, 2191-2198.

[32] Leroueil, P.R.; Berry, S.A.; Duthie, K.; Han, G.; Rotello, V.M.; McNerny, D.Q.; Baker, J.R.; Orr, B.G.; BanaszakHoll, M.M. Wide Varieties of Cationic Nanoparticles Induce Defects in Supported Lipid Bilayers. Nano Lett 2008 8, 420-424.

[33] Mecke, A.; Majoros, I.J.; Patri, A.K.; Baker, J.R.; BanaszakHoll, M.M.; Orr, B.G. Lipid Bilayer Disruption by Polycationic Polymers: The Roles of Size and Chemical Functional Group. Langmuir 2005 21, 10348-10354.

[34] Hong, S.; Bielinska, A.U.; Mecke, A.; Keszler, B.; Beals, J.L.; Shi, X.; Balogh, L.; Orr, B.G.; Baker, J.R.; BanaszakHoll, M.M. Interaction of Poly(amidoamine) Dendrimers with Supported Lipid Bilayers and Cells: Hole Formation and the Relation to Transport. Bioconjugate Chem 2004 15, 774-782.

[35] Patel, A.R.; Frank, C.W. Quantitative Analysis of Tethered Vesicle Assemblies by Quartz Crystal Microbalance with Dissipation Monitoring: Binding Dynamics and Bound Water Content. Langmuir 2006 22, 7587-7599.

[36] Rodahl, M.; Kasemo, B. A simple setup to simultaneously measure the resonant frequency and the absolute dissipation factor of a quartz crystal microbalance. Rev Sci Instrum 1996 67, 32383241.

[37] Krozer, A.; Rodahl, M. X-ray photoemission spectroscopy study of UV/ozone oxidation of Au under ultrahigh vacuum conditions. J Vac Sci Technol A 1997 15, 1704-1709. 
[38] Harewood, K.; Wolff, J.S.I. A rapid electrophoretic procedure for the detection of SDS-released oncorna-viral RNA using polyacrylamide-agarose gels. Anal Biochem 1973 55, 573-581.

[39] Penfold, J.; Staples, E.; Tucker, I.; Thomas, R.K. Adsorption of Mixed Anionic and Nonionic Surfactants at the Hydrophilic Silicon Surface. Langmuir 2002 18, 5755-5760.

C 2008 by MDPI (http://www.mdpi.org). Reproduction is permitted for noncommercial purposes. 